\title{
Identification of urinary tract pathogens after 3-hours urine culture by MALDI-TOF mass spectrometry
}

\section{Haiko, Johanna}

2016-10

Haiko , J , Savolainen , L E , Hilla , R \& Patari-Sampo , A 2016 , ' Identification of urinary tract pathogens after 3-hours urine culture by MALDI-TOF mass spectrometry ' , Journal of Microbiological Methods , vol. 129 , pp. 81-84 . https://doi.org/10.1016/j.mimet.2016.08.006

http://hdl.handle.net/10138/225927

https://doi.org/10.1016/j.mimet.2016.08.006

publishedVersion

Downloaded from Helda, University of Helsinki institutional repository.

This is an electronic reprint of the original article.

This reprint may differ from the original in pagination and typographic detail.

Please cite the original version. 


\title{
Identification of urinary tract pathogens after 3-hours urine culture by MALDI-TOF mass spectrometry
}

\author{
Johanna Haiko, Laura E. Savolainen, Risto Hilla, Anu Pätäri-Sampo * \\ Department of Clinical Microbiology, University of Helsinki and Helsinki University Hospital, HUSLAB, Helsinki, Finland
}

\section{A R T I C L E I N F O}

\section{Article history:}

Received 2 June 2016

Received in revised form 4 August 2016

Accepted 4 August 2016

Available online 5 August 2016

\section{Keywords:}

Urinary tract infection

Rapid identification

Urine culture

MALDI-TOF

\begin{abstract}
A B S T R A C T
Complicated urinary tract infections, such as pyelonephritis, may lead to sepsis. Rapid diagnosis is needed to identify the causative urinary pathogen and to verify the appropriate empirical antimicrobial therapy. We describe here a rapid identification method for urinary pathogens: urine is incubated on chocolate agar for $3 \mathrm{~h}$ at $35^{\circ} \mathrm{C}$ with $5 \% \mathrm{CO}_{2}$ and subjected to MALDI-TOF MS analysis by VITEK MS. Overall 207 screened clinical urine samples were tested in parallel with conventional urine culture. The method, called U-si-MALDI-TOF (urine short incubation MALDI-TOF), showed correct identification for $86 \%$ of Gram-negative urinary tract pathogens (Escherichia coli, Klebsiella pneumoniae, and other Enterobacteriaceae), when present at $>10^{5} \mathrm{cfu} / \mathrm{ml}$ in culture $(n=107)$, compared with conventional culture method. However, Gram-positive bacteria $(n=28)$ were not successfully identified by U-si-MALDI-TOF. This method is especially suitable for rapid identification of $E$. coli, the most common cause of urinary tract infections and urosepsis. Turnaround time for identification using Usi-MALDI-TOF compared with conventional urine culture was improved from $24 \mathrm{~h}$ to 4-6 h.
\end{abstract}

(c) 2016 Elsevier B.V. All rights reserved.

\section{Introduction}

After respiratory tract infections, urinary tract infections (UTI) are the second most common community-acquired infections that lead to health care visits in the United States (Schappert \& Rechtsteiner, 2011). Also hospital-acquired UTIs comprise as much as 36\% of nosocomial infections in the U.S. (Klevens et al., 2007), and about 9-31\% of sepsis cases originate from urinary tract infections (Levy et al., 2012). Urosepsis risk is increased in persons who are elderly, immunocompromised, diabetic, pregnant, or carry structural urinary tract abnormalities. Urosepsis may lead to severe sepsis and septic shock and its mortality rate is around 5\% (Foxman, 2014). Of patients with acute pyelonephritis, only about 20-30\% show positive blood cultures (Sandberg et al., 2012), and thus the definitive diagnosis for the rest of the pyelonephritis patients relies on the urine culture.

Most often UTI are caused by one bacterial species: in about $80 \%$ of cases the causative agent is Escherichia coli. In typical laboratory UTI diagnostics, the pathogen is identified in $24 \mathrm{~h}$, and the antibiotic susceptibility testing (AST) results become available in $48 \mathrm{~h}$. First, the patients

\footnotetext{
Abbreviations: AST, antibiotic susceptibility testing; MALDI-TOF MS, matrix-assisted laser desorption/ionization time-of-flight mass spectrometry; SI, short incubation; UTI, urinary tract infection; cfu, colony forming unit.

* Corresponding author.

E-mail addresses: johanna.haiko@alumni.helsinki.fi (J. Haiko), laura.e.savolainen@hus.fi (L.E. Savolainen), risto.hilla@hus.fi (R. Hilla), anu.patari-sampo@hus.fi (A. Pätäri-Sampo).
}

are treated empirically, and the antibiotic will be changed according to the susceptibility results when necessary.

Several rapid diagnostic methods for identification of pathogens in urine samples have been introduced recently (Ferreira et al., 2010, 2011; Köhling et al., 2012; Burillo et al., 2014; DeMarco and Burnham, 2014; Kim et al., 2015; Veron et al., 2015; Íñigo et al., 2016). However, all these methods include laborious pre-handling, e.g. centrifugation or filtration steps, to get rid of other urine components, before MALDITOF MS analysis. This is problematic for many clinical laboratories that analyze hundreds of specimens daily. Minimal hands-on time is thus appreciated and essential to implement a new method for daily routine.

A rapid method for identification of bacteria from positive blood culture bottles, called si-MALDI-TOF MS (short incubation matrix-assisted laser desorption/ionization time-of-flight mass spectrometry) has recently been introduced (Bhatti ${ }^{-}{ }^{-}$al., 2014; Kalanti et al., 2014; Kohlmann et al., 2015; Zabbe et al., 2015). In this method a few drops of blood from a positive blood culture bottle were incubated for a short time (3-4 h) on a conventional chocolate agar and subjected to MALDI-TOF MS even without visible colonies. By this method, Gramnegative bacteria were correctly identified in $87 \%$ and Gram-positive bacteria in $69 \%$ of the samples tested. E. coli was correctly identified in 91.5\% of the samples (Kalanti et al., 2014).

Based on these results regarding blood cultures, we tested whether a 3-h si-MALDI-TOF method could be useful for typically acquired clinical urine samples to reduce the turnaround time for the pathogen identification. 
Table 1

Types of the clinical urine samples.

\begin{tabular}{ll}
\hline Sample type & $n(\%)$ \\
\hline Voided midstream & $157(76)$ \\
Intermittent catheter & $16(8)$ \\
Permcatch & $8(4)$ \\
Suprapubic catheter & $4(2)$ \\
Pyelostoma & $2(1)$ \\
Urine collection bag & $2(1)$ \\
Stoma & $1(0)$ \\
Not known & $17(8)$ \\
Total & $207(100)$ \\
\hline
\end{tabular}

\section{Materials and methods}

\subsection{Clinical samples}

The urine samples (Table 1 ), routinely submitted to the Department of Bacteriology of Helsinki University Central Hospital HUSLAB for urine culture, were analyzed. We selected samples that had shown positive leukocyte and/or bacteria result $\left(>10 \times 10^{3}\right.$ leukocytes $/ \mathrm{ml}$ and $>70 \times 10^{3}$ bacteria $/ \mathrm{ml}$ ) provided by Sysmex UF-1000i automated flow cytometer (Sysmex America Inc., Lincolnshire, Illinois, USA) or positive leukocyte (at least $2 \times 10^{10}$ leukocytes $/ \mathrm{ml}$ ) in the Urine Dipstick Analysis done by The Department of Clinical Chemistry and Hematology at HUSLAB. The samples were collected into BD Vacutainer ${ }^{\circledR}$ Preservative tubes (Becton Dickinson and Company, Franklin Lakes, New Jersey, USA) and stored overnight at $4{ }^{\circ} \mathrm{C}$.

\subsection{Conventional urine culture}

Urine was inoculated onto $\mathrm{BD}^{\mathrm{TM}}$ CHROMagar ${ }^{\mathrm{TM}}$ Orientation (Becton Dickinson and Company) plate using a $1 \mu \mathrm{l}$ calibrated loop (Berner Pro, Helsinki, Finland) and incubated at $35^{\circ} \mathrm{C}$ in ambient air for $18 \mathrm{~h}$ according to our standard urine culture protocol. One or two significant UTI pathogens were identified by routine MALDI-TOF MS (bioMérieux, Marcy l'Etoile, France) from individual colonies. E. coli was identified either by the color reaction on CHROMagar or by routine MALDI-TOF MS. When three or more organisms were observed, the result was interpreted as mixed flora. The amount of bacteria $(\mathrm{cfu} / \mathrm{ml})$ was derived by counting colonies on the CHROMagar plate, $>10-100$ colonies inoculated with a $1 \mu$ loop representing $10^{4}-10^{5} \mathrm{cfu} / \mathrm{ml}$ in the urine sample, and $>100$ colonies representing $>10^{5} \mathrm{cfu} / \mathrm{ml}$.

\subsection{Sample preparation for U-si-MALDI-TOF and routine MALDI-TOF} analysis

The samples were mixed by inverting the tubes a few times, and $200 \mu \mathrm{l}$ of urine was pipetted on chocolate agar plate as a spot. Two spots per sample were performed. The plates were incubated at $35^{\circ} \mathrm{C}$ with $5 \% \mathrm{CO}_{2}$ for $3 \mathrm{~h}$. After incubation, a sample from the spot area with visible or invisible growth was taken with a $1 \mu \mathrm{l}$ loop to the MALDI-TOF target plate. The spot was subjected to routine MALDI-TOF MS with $1 \mu \mathrm{l}$ of $\alpha$-cyano-4-hydroxycinnamic acid (CHCA) matrix and air-drying at room temperature. MALDI-TOF MS measurements were performed on VITEK MS mass spectrometer (bioMérieux) and analyzed against the IVD database by MYLA Software (bioMérieux). The VITEK MS IVD database consists of ca. 750 clinically relevant species with an average of $>14$ isolates/species and 36 mass spectra/species. The results appear as percentages, $99.9 \%$ being the highest value. The identification was accepted when $\geq 97.5 \%$ identification was detected in at least one of the duplicate spots, and when the species identified was a potential uropathogen. However, if the results were discordant in the duplicate spots (two different species), or if the identification resulted in species that does not grow on CHROMagar or on chocolate agar or was not a uropathogen, the sample was regarded as negative.

\section{Results}

Two hundred seven screening test positive urine samples were analyzed in parallel with U-si-MALDI-TOF and conventional culture. In conventional urine culture, 16 samples were negative, 49 samples grew mixed flora, and 142 samples showed significant growth $\left(>10^{5}\right.$ or $10^{4-5} \mathrm{cfu} / \mathrm{ml}$ ) of one colony morphology. Compared to conventional urine culture, the overall sensitivity of U-si-MALDI-TOF was $67 \%$ and specificity $79 \%$ for the detection of uropathogens. Positive predictive value of the test was $87 \%$ and negative predictive value $55 \%$.

Of the 142 samples showing significant growth, E. coli $>10^{5} \mathrm{cfu} / \mathrm{ml}$ represented the majority (87/142), and U-si-MALDI-TOF successfully identified 75 (86\%) of them (Table 2). Of the rest of the samples with E. coli $>10^{5} \mathrm{cfu} / \mathrm{ml}, 11$ (13\%) were negative with U-si-MALDI-TOF, and one gave a U-si-MALDI-TOF result of Citrobacter sp. instead of $E$. coli. This E. coli was identified in conventional culture by the red color reaction on CHROMagar, not by MALDI-TOF MS. Only one (14\%) sample with $10^{4-5} \mathrm{cfu} / \mathrm{ml}$ of $E$. coli was correctly identified by U-si-MALDITOF, and the rest consisting of six samples (86\%) gave negative results. Unspecific recognition with poor identification percentage or bacteria of the normal microbiota of the urogenital tract (Lactobacillus sp., Gardnerella vaginalis, Bacillus badius, Clostridium ramosum) were

Table 2

Accuracy of U-si-MALDI-TOF for identification of Gram-negative bacteria.

\begin{tabular}{|c|c|c|c|c|}
\hline Culture result $\mathrm{cfu} / \mathrm{ml}$ & $n$ & $\begin{array}{l}\text { U-si-MALDI-TOF correct identification } \\
n(\%)\end{array}$ & $\begin{array}{l}\text { U-si-MALDI-TOF discordant result } \\
n(\%)\end{array}$ & $\begin{array}{l}\text { U-si-MALDI-TOF negative } \\
n(\%)\end{array}$ \\
\hline Escherichia coli $>10^{5}$ & $87^{\mathrm{a}}$ & $75(86)$ & $1(1)^{d}$ & $11(13)$ \\
\hline Escherichia coli $10^{4-5}$ & $7^{\mathrm{b}}$ & $1(14)$ & $0(0)$ & $6(86)$ \\
\hline Klebsiella pneumoniae $>10^{5}$ & $7^{c}$ & $7(100)$ & $0(0)$ & $0(0)$ \\
\hline Klebsiella oxytoca $>10^{5}$ & $3^{c}$ & $2(67)$ & $1(33)^{e}$ & $0(0)$ \\
\hline Citrobacter sp. $>10^{5}$ & $3^{c}$ & $3(100)$ & $0(0)$ & $0(0)$ \\
\hline Enterobacter sp. $>10^{5}$ & $4^{c}$ & $3(75)$ & $0(0)$ & $1(25)$ \\
\hline Pseudomonas aeruginosa $>10^{5}$ & $1^{\mathrm{c}}$ & $1(100)$ & $0(0)$ & $0(0)$ \\
\hline Proteus mirabilis $>10^{5}$ & $1^{\mathrm{c}}$ & $1(100)$ & $0(0)$ & $0(0)$ \\
\hline Morganella morganii $>10^{5}$ & $1^{\mathrm{c}}$ & $0(0)$ & $0(0)$ & $1(100)$ \\
\hline
\end{tabular}

a 86 identified by CHROMagar reaction and 6 by MALDI-TOF.

b 6 identified by CHROMagar reaction and 1 by MALDI-TOF.

c Identified by MALDI-TOF.

d Citrobacter sp. $1 \times 97.5 \%$.

e Proteus vulgaris/penneri. 
identified in one of the duplicate spots in four samples. These were interpreted as negative.

In 20 samples, a Gram-negative rod other than E. coli $\left(>10^{5} \mathrm{cfu} / \mathrm{ml}\right)$ was identified by conventional culture. Of those, 17 (85\%) were correctly identified by U-si-MALDI-TOF. K. pneumoniae was successfully identified in $7 / 7$ (100\%) samples. One Klebsiella oxytoca was incorrectly identified as Proteus sp. by U-si-MALDI-TOF. Furthermore, one Enterobacter sp. and one Morganella morganii gave negative results by U-siMALDI-TOF.

U-si-MALDI-TOF did not perform as well in samples with Gram-positive bacteria (growth $>10^{5}$ or $10^{4-5} \mathrm{cfu} / \mathrm{ml}$ ). From 28 conventional cultures that generated Gram-positive growth, 14 were identified as Enterococcus faecalis by routine MALDI-TOF MS; only one of these was correctly identified using U-si-MALDI-TOF assay. All other samples analyzed by U-si-MALDI-TOF gave a false negative result (Table 3 ).

The conventional culture resulted in mixed flora in 49/207 samples, most of which represented voided midstream urine samples. Of the mixed flora samples, 37 (67\%), were regarded as negative in U-siMALDI-TOF assay. Of those, 27 samples gave no result, and 10 samples showed unspecific recognition with "impossible" result, discordant result in duplicate spots and/or poor identification percentage, or species that was not a uropathogen. E. coli was detected in six samples, and other Gram-negative rods in six samples (Enterobacter aerogenes, Morganella morganii, Proteus vulgaris/penneri, Serratia marcescens, and two Klebsiella pneumoniae) by U-si-MALDI-TOF in both duplicate spots in the mixed flora samples. All culture negative samples $(16 / 207)$ were negative also in U-si-MALDI-TOF analysis.

\section{Discussion}

Using U-si-MALDI-TOF we were able to correctly identify 86\% (92/ 107 ) of the Gram-negative urinary pathogens in samples with bacterial load of $>10^{5} \mathrm{cfu} / \mathrm{ml}$. Our results suggest that short incubation combined with MALDI-TOF MS might be useful for the identification of Gram-negative urinary pathogens, in particular $E$. coli, when urine bacterial count is $>10^{5} \mathrm{cfu} / \mathrm{ml}$. This is in line with previous findings regarding similar methods (Ferreira et al., 2010, 2011; DeMarco and Burnham, 2014; Veron et al., 2015). We propose that this method can be used in attempting to diagnose patients with suspected pyelonephritis and urosepsis when rapid diagnosis is invaluable and the amount of bacteria in urine is usually high; however, further evaluation is needed for samples of patients with these diagnoses. Under certain clinical situations, such as samples of the pyelostomy or paracentesis of the urinary bladder, a cfu/ml value less than $10^{5}$ could be significant, and in these cases, conventional urine culture would be recommended instead of U-si-MALDI-TOF analysis.

The conventional urine culture, in which the bacteria are identified on the basis of the color reaction on chromogenic agar or with MALDITOF MS, requires an overnight incubation. The final result with antibiotic susceptibility is usually available after $48 \mathrm{~h}$. The use of various tests, such as nitrite, leukocyte, and/or bacterial count and Gram staining have been assessed for rapid identification of bacteria from urine samples (Ferreira et al., 2010; Burillo et al., 2014; Veron et al., 2015).
However, the sensitivity, specificity, and hands-on time of these tests varies. Using U-si-MALDI-TOF we were able to shorten the turnaround time of the identification process of Gram-negative urinary pathogens from $24 \mathrm{~h}$ to $4-6 \mathrm{~h}$.

In complicated UTI it is critical to know the causative pathogen to be able to change the empirical antibiotic treatment accordingly. This is important when, e.g. P. aeruginosa or another AmpC-producing species, such as Enterobacter cloacae, Citrobacter sp., or M. morganii, is involved. Unfortunately we only had one P. aeruginosa sample in our study, anyhow it was correctly identified. Overall, the amount of Gram-negative rods other than E. coli was rather small in our analysis, and this needs further investigation.

The si-MALDI-TOF of positive blood cultures correctly identifies $87 \%$ of Gram-negative bacteria and 69\% of Gram-positive bacteria (Kalanti et al., 2014). Notably, the bacterial amount in a positive blood culture bottle is higher $\left(10^{6}-10^{9} \mathrm{cfu} / \mathrm{ml}\right)$ compared with the bacterial load in a typical urine sample $\left(10^{3}-10^{6} \mathrm{cfu} / \mathrm{ml}\right)$. This may be the reason why Grampositive bacteria failed to be identified using U-si-MALDI-TOF. Use of collection tubes with preservative agents may alter the amount of Gram-positive bacteria more than that of Gram-negative bacteria.

The use of MALDI-TOF MS for direct identification of urinary tract pathogens has been evaluated by few studies, but typically these methods require various sample preparation protocols, such as centrifugation or filtration steps (Ferreira et al., 2010, 2011; Köhling et al., 2012; Burillo et al., 2014; DeMarco and Burnham, 2014; Kim et al., 2015; Veron et al., 2015; Íñigo et al., 2016). Our method is able to avoid laborious pre-handling steps maybe because the components that disturb the MS analysis are either absorbed into the solid medium or lysed during the incubation. The advantages of this method are its rapidness, easiness, and minimal hands-on time. The only significant cost is the purchase of MALDI-TOF mass spectrometer, which is however already routinely used in many clinical laboratories in the Western countries nowadays.

U-si-MALDI-TOF would complement the diagnostics of urosepsis, especially when combined with rapid AST. Rapid AST made directly from the urine sample by disk diffusion would reduce the turnaround time with several hours to $<24 \mathrm{~h}$, and this has actually been tested by Enterobacteriaceae with good results (Sundqvist et al., 2015). Also other methods, such as isothermal microcalorimetry (Braissant et al., 2014) and 16S rRNA based method (Mezger et al., 2015) have been successfully applied for rapid AST from the urine samples. Combining rapid identification with rapid AST could improve the treatment results of urosepsis patients and even reduce the time and costs of hospital stays.

\section{Conclusions}

U-si-MALDI-TOF MS is a reliable rapid method for the identification of the Gram-negative bacteria, the most common causative agents of UTI and urosepsis. In the future, the method could be incorporated to the diagnostic work-up of pyelonephritis and sepsis when rapid identification of urinary pathogens is needed. Combined with rapid AST, it could significantly advance the diagnostics of UTI and reduce related morbidity and mortality.

Table 3

Accuracy of U-si-MALDI-TOF for identification of Gram-positive bacteria.

\begin{tabular}{|c|c|c|c|}
\hline $\begin{array}{l}\text { Culture result cfu/ml } \\
\text { (identified by MALDI-TOF MS) }\end{array}$ & $n$ & $\begin{array}{l}\text { U-si-MALDI-TOF correct identification } \\
n(\%)\end{array}$ & $\begin{array}{l}\text { U-si-MALDI-TOF negative } \\
n(\%)\end{array}$ \\
\hline Staphylococcus aureus $>10^{5}$ & 3 & $0(0)$ & $3(100)$ \\
\hline Enterococcus faecalis $10^{4-5} />10^{5}$ & 14 & $1(7)$ & $13(93)$ \\
\hline Staphylococcus epidermidis $>10^{5}$ & 2 & $0(0)$ & $2(100)$ \\
\hline Streptococcus agalactiae $10^{4-5} />10^{5}$ & 4 & $0(0)$ & $4(100)$ \\
\hline Streptococcus viridans $10^{4-5}$ & 1 & $0(0)$ & $1(100)$ \\
\hline Lactobacillus sp. $>10^{5}$ & 4 & $0(0)$ & $4(100)$ \\
\hline
\end{tabular}




\section{Acknowledgements}

We thank Rami Lehmusto for technical assistance. We also thank the Department of Clinical Microbiology (HUSLAB, Finland) for providing the facilities for this research.

\section{References}

Bhatti, M.M., Boonlayangoor, S., Beavis, K.G., Tesic, V., 2014. Rapid identification of positive blood cultures by matrix-assisted laser desorption ionization-time of flight mass spectrometry using prewarmed agar plates. J. Clin. Microbiol. 52 (12), 4334-4338. http://dx.doi.org/10.1128/JCM.01788-14.

Braissant, O., Müller, G., Egli, A., Widmer, A., Frei, R., Halla, A., Wirz, D., Gasser, T.C. Bachmann, A., Wagenlehner, F., Bonkat, G., 2014. Seven hours to adequate antimicrobial therapy in urosepsis using isothermal microcalorimetry. J. Clin. Microbiol. 52 (2), 624-626. http://dx.doi.org/10.1128/JCM.02374-13.

Burillo, A., Rodríguez-Sánchez, B., Ramiro, A., Cercenado, E., Rodríguez-Créixems, M., Bouza, E., 2014. Gram-stain plus MALDI-TOF MS (Matrix-Assisted Laser Desorption Ionization-Time of Flight Mass Spectrometry) for a rapid diagnosis of urinary tract infection. PLoS One 9 (1), e86915. http://dx.doi.org/10.1371/journal.pone.0086915.

DeMarco, M.L., Burnham, C.A.D., 2014. Diafiltration MALDI-TOF mass spectrometry method for culture-independent detection and identification of pathogens directly from urine specimens. Am. J. Clin. Pathol. 141, 204-212. http://dx.doi.org/10.1309/ AJCPQYW3B6JLKILC.

Ferreira, L., F. Sánchez-Juanes, F., González-Ávila, M., Cembrero-Fuciños, D., HerreroHernández, A., JM, G.-B., JL, M.-B., 2010. Direct identification of urinary tract pathogens from urine samples by matrix-assisted laser desorption ionization-time of flight mass spectrometry. J. Clin. Microbiol. 48 (6), 2110-2115. http://dx.doi.org/10.1128/ JCM.02215-09.

Ferreira, L., F. Sánchez-Juanes, F., JL, M.-B., JM, G.-B., 2011. Rapid method for direct identification of bacteria in urine and blood culture samples by matrix-assisted laser desorption ionization time-of-flight mass spectrometry: intact cell vs. extraction method. Clin. Microbiol. Infect. 17, 1007-1012. http://dx.doi.org/10.1111/j.14690691.2010.03339.x

Foxman, B., 2014. Urinary tract infection syndromes: occurrence, recurrence, bacteriology, risk factors, and disease burden. Infect. Dis. Clin. N. Am. 28 (1), 1-13. http://dx. doi.org/10.1016/j.idc.2013.09.003.

Íñigo, M., Coello, A., Fernández-Rivas, G., Rivaya, B., Hidalgo, J., Quesada, M.D., Ausina, V., 2016. Direct identification of urinary tract pathogens from urine samples, combining urine screening methods and matrix-assisted laser desorption ionization-time of flight mass spectrometry. J. Clin. Microbiol. 54 (4), 988-993. http://dx.doi.org/10. 1128/JCM.02832-15.

Kalanti, A., Oksaharju, A., Rantakokko-Jalava, K., Kuusela, P., 2014. Rapid Pathogen Identification in Blood Cultures by Means of Short-Incubation MALDI-TOF (SI-MALDI-TOF). Poster, ECCMID, Barcelona, Spain.
Kim, Y., Park, K.G., Lee, K., Park, Y.J., 2015. Direct identification of urinary tract pathogens from urine samples using the Vitek MS system based on matrix-assisted laser desorption ionization-time of flight mass spectrometry. Ann. Lab. Med. 35 (4), 416-422. http://dx.doi.org/10.3343/alm.2015.35.4.416.

Klevens, R.M., Edwards, J.R., Richards Jr., C.L., Horan, T.C., Gaynes, R.P., Pollock, D.A., Cardo, D.M., 2007. Estimating health care-associated infections and deaths in U.S. hospitals, 2002. Public Health Rep. 122 (2), 160-166.

Köhling, H.L., Bittner, A., Müller, K.D., Buer, J., Becker, M., Rübben, H., Rettenmeier, A.W. Mosel, F., 2012. Direct identification of bacteria in urine samples by matrix-assisted laser desorption/ionization time-of-flight mass spectrometry and relevance of defensins as interfering factors. J. Med. Microbiol. 61, 339-344. http://dx.doi.org/10. 1099/jmm.0.032284-0.

Kohlmann, R., Hoffmann, A., Geis, G., Gatermann, S., 2015. MALDI-TOF mass spectrometry following short incubation on a solid medium is a valuable tool for rapid pathogen identification from positive blood cultures. Int. J. Med. Microbiol. 305 (4-5) 469-479. http://dx.doi.org/10.1016/j.ijmm.2015.04.004.

Levy, M.M., Artigas, A., Phillips, G.S., Rhodes, A., Beale, R., Osborn, T., Vincent, J.-L., Townsend, S., Lemeshow, S., Dellinger, R.P., 2012. Outcomes of the surviving sepsis campaign in intensive care units in the USA and Europe: a prospective cohort study. Lancet Infect. Dis. 12, 919-924. http://dx.doi.org/10.1016/S14733099(12)70239-6.

Mezger, A., Gullberg E., Göransson, J., Zorzet, A., Herthnek, D., Tano, E, Nilsson, M. Andersson, D.I., 2015. A general method for rapid determination of antibiotic susceptibility and species in bacterial infections. J. Clin. Microbiol. 53, 425-432. http://dx. doi.org/10.1128/JCM.02434-14.

Sandberg, T., Skoog, G., Hermansson, A.B., Kahlmeter, G., Kuylenstierna, N., Lannergård, A. Otto, G., Settergren, B., Ekman, G.S., 2012. Ciprofloxacin for 7 days versus 14 days in women with acute pyelonephritis: a randomised, open-label and double-blind, placebo-controlled, non-inferiority trial. Lancet 380 (9840), 484-490. http://dx.doi.org 10.1016/S0140-6736(12)60608-4.

Schappert, S.M., Rechtsteiner, E.A., 2011. Ambulatory medical care utilization estimates for 2007. Vital Health Stat. 13 (169), 1-38.

Sundqvist, M., Olafsson, J., Matuschek, E., 2015. EUCAST breakpoints can be used to interpret direct susceptibility testing of Enterobacteriaceae from urine samples. APMIS 123 (2), 152-155. http://dx.doi.org/10.1111/apm.12331.

Veron, L., Mailler, S., Girard, V., Muller, B.H., L'Hostis, G., Ducruix, C., Lesenne, A., Richez, A. Rostaing, H., Lanet, V., Ghirardi, S., van Belkum, A., Mallard, F., 2015. Rapid urine preparation prior to identification of uropathogens by MALDI-TOF MS. Eur. J. Clin. Microbiol. Infect. Dis. 34 (9), 1787-1795. http://dx.doi.org/10.1007/s10096-015 2413-y.

Zabbe, J.B., Zanardo, L., Mégraud, F., Bessède, E., 2015. MALDI-TOF mass spectrometry for early identification of bacteria grown in blood culture bottles. J. Microbiol. Methods 115, 45-46. http://dx.doi.org/10.1016/j.mimet.2015.04.009. 